\title{
Respuesta a Carta al Director
}

\section{Sr. Director:}

He leído la Carta al Director firmada por Ricard Mesia Nin, Margarita García Martín y Joseph Ramón Germá Lluch en la que, en respuesta a mi editorial' se critican cosas que en el editorial no se dicen.

De ninguna manera en el editorial se dice que los estudios piloto sean superiores a los randomizados. Los estudios piloto, por el contrario, deben ser la base del diseño de nuevos tratamientos que, posteriormente, deben verificarse mediante estudios randomizados. Lo que ocurre es que, dado que los estudios que se llevan a cabo requieren mucho tiempo y esfuerzo, muchos equipos implicados en el tratamiento del cáncer de cabeza y cuello y que, lógicamente, quieren avanzar en su campo, prefieren realizar estudios randomizados comparando esquemas de tratamiento con poca base cinética a intentar nuevos estudios piloto que puedan aprovechar en la clínica conocimientos cinéticos que antes no hayan intervenido en el diseño de otros estudios, con lo que no se fomenta el desarrollo de nuevos esquemas de tratamiento que podrían mejorar el arsenal terapéutico. Randomizar sin base suficiente para ello no es parte del método científico sino una perversión del mismo, ya que puede darse el caso, cosa común por otra parte, de comparar, como acabo de mencionar, dos esquemas de tratamiento, ambos con escasa base cinética, con lo que el concluir que uno de ellos es mejor que el otro nos deja todavía lejos de haber contribuido al aprovechamiento integral de los recursos que, en teoría, ofrece la interacción radioquimioterápica. Los esquemas de radioquimioterapia actuales están lejos del esquema óptimo que todos desearíamos aplicar. Si, con semejante base, solamente efectuamos estudios randomizados, estaremos consumiendo todo el tiempo y todos los recursos que podrían aplicarse al método científico en determinar qué tratamiento no óptimo es superior a otro tratamiento tampoco óptimo. El método científico nos obliga a intentar acercarnos al esquema o esquemas óptimos y para ello no hay mas remedio que efectuar estudios que aprovechen conocimientos biológicos que todavía no se hayan aplicado, o sea, estudios fase II. Todo sin perivicio de que esos nuevos esquemas deban someterse después a estudios randomizados. Creo, pues, que para seguir el método científico de forma integral se deben fomentar, además de estudios randomizados, estudios piloto que suministren la base de nuevas randomizaciones.

Como ejemplo de estudio randomizado que constituye, según mi opinión, una perversión del método científico, está el mencionado por los autores de la carta $^{2}$ que considero un caso claro de que, mal diseñada, la randomización puede perjudicar el avance científico. Además de las fuertes críticas que ha recibido el estudio y que creo que lo dejan sin valor práctico, el estudio presenta también los siguientes defectos que no he visto reseñados en las críticas publicadas y que cada uno de los cuales, según mi criterio, lo invalida por sí mismo:

1) La técnica de irradiación no ha sido la misma para todos los pacientes de todos los centros que presentaban enfermedad de iguales características.

2) Los pacientes entrados por cada centro no han sido consecutivos dentro del mismo.

3) Se acepta como correcta una técnica de radioterapia que no incluye los márgenes de seguridad en el volumen blanco.

4) El número de violaciones en la técnica de radioterapia y de control locorregional no evaluados no está en consonancia con el número de casos evaluados como receptores de una técnica de radioterapia correcta, a menos que los autores incluyeran como técnica correcta varias decenas de casos de violaciones o de no evaluación de control locorregional.

5) Además, el $39 \%$ de los pacientes fueron excluidos del análisis final después de ser randomizados.

Repito que cada una de estas circunstancias debería, por sí sola, invalidar el estudio y estoy convencido de que, en estas condiciones, los autores no lo deberían haber llevado a cabo.

Sin embargo, el tal estudio ha iniciado en la prácti- 
ca una controversia de fuertes proporciones a causa, exclusivamente, de la tendencia general a aceptar como válidos los estudios randomizados a pesar de que el estudio que nos ocupa, de randomizado sólo tiene el nombre porque su diseño, desarrollo y valoración contradicen el método que un estudio randomizado debe seguir. La controversia originada está perjudicando seriamente la valoración objetiva de un procedimiento terapéutico que, si bien no definitivamente probado, venía precedido de conocimientos de múltiples fuentes y sólidamente adquiridos a lo largo de los años y que debía haber sido sometido a un estudio randomizado riguroso.

En conclusión, la randomización es un paso fundamental para la validación de un esquema terapéutico pero debe ser el final de una cadena y no el principio de la misma como, lamentablemente, cada vez observamos con mayor frecuencia. Además, la randomización debe aplicarse con rigor metodológico y no sólo como escaparate de nomenclatura. Asimismo, el aprovechamiento integral de los recursos que ofrece la interacción de la radioterapia y quimioterapia, exige tanto la realización de estudios piloto nuevos como la realización de estudios randomizados.

En todo caso, aconsejamos a los autores que, si disponen de algún tiempo, se lean de nuevo el editorial. Para mí representaría un gran honor y a ellos les daría la oportunidad de criticar lo que se dice en lugar de criticar lo que no se menciona.

\section{Dr. Alfonso Villar Rodríguez}

\section{Bibliografía}

1. Villar A. Pasado, presente y futuro del tratamiento conservador del cáncer de cabeza y cuello. Oncología 2004: 27:1-3.

2. Henke M, Laszig, Rübe $C$, et al. Erythropoietin to treat head and neck cancer patients with anemia undergoing radiotherapy: randomised, double-blind, placebo-controlled tril. Lancet 2003; 362: 1255-60. 